\title{
Health information systems for leprosy control programmes: a case for quality assessment
}

\author{
DANIEL GRODOS, ISABELLE FRANÇOIS \\ \& RENÉ TONGLET \\ Catholic University of Louvain, Faculty of Medicine, \\ School of Public Health, Epidemiology Unit (UCL 30.34), \\ Clos Chapelle aux Champs, 30 B-1200 Brussels, Belgium
}

\section{Accepted for publication 13 February 1996}

\begin{abstract}
Summary A qualitative study was carried out aimed at checking the level of understanding and the actual use of the indicators recommended in leprosy control programmes by either the World Health Organization or the International Federation of Anti-Leprosy Associations. Two successive questionnaires were sent to 268 leprosy control programme managers. The first one concerned information about the main characteristics of the programme, the information system in operation, and the data regarded as indispensable or usef ul for programme monitoring. The respondents to the first questionnaire $(n=64)$ proposed an extraordinarily wide range of indicators, mainly ill-defined. The respondents to the second questionnaire $(n=37)$ to whom a limited list of precisely defined indicators was submitted did not succeed in reaching a complete agreement on any of these indicators. Although the question of programme monitoring has been dealt with at an international level for years, there is an urgent need for a real agreement of international agencies and managers of leprosy control programmes on the indicators to be used. Programme managers in the field are obviously open to the idea of greater intervention by international organizations to improve data collection and to encourage standardization of computerized information systems.
\end{abstract}

\section{Introduction}

In 1991, the 44th World Health Assembly adopted a resolution on the elimination of leprosy as a public health problem by the year 2000. ${ }^{1,2}$ Elimination was defined as a level of prevalence below 1 case per 10,000 population. One important issue of the elimination goal is the strengthening of resource management in leprosy control programmes. This includes the promotion of an adequate use of the internationally recommended indicators for programme evaluation. The World Health Organization (WHO) and the International Federation of Anti-leprosy Associations (ILEP) have been tackling this question for a long time..$^{3-6}$ The International Meeting on Epidemiology of Leprosy 
in Relation to Control, held in Jakarta in June 1991, also dealt with this problem. ${ }^{7-9}$ Yet, the 14th International Congress on Leprosy, held in Orlando (USA) in AugustSeptember 1993, hardly addressed the question. ${ }^{10}$

While international organizations usually deal with programme monitoring in a normative way, in the search for the 'best set' of indicators to be recommended, it seems that little attention is paid to the question of whether and how far these indicators are used and understood by health workers and health programme managers in the field. If programme monitoring and evaluation as well as epidemiological surveillance have to be carried out using information collected routinely, ${ }^{11}$ it should not be overlooked that no statistical manipulation can compensate for the poor quality of primary data.

We report here on a qualitative study designed to measure the understanding and actual use of the indicators recommended by either WHO or ILEP. This analysis is part of a larger study on health information systems for leprosy control, including more specifically the OMSLEP system. ${ }^{12}$ By information system we mean an integrated set of files, procedures and equipment aimed at storing, processing and retrieving relevant health information. The specific objectives of the present study were as follows: to check which indicators are considered by the programme managers as indispensable, useful, or pointless for leprosy control; to verify whether a consensus is reached in the field on the recommended set of basic indicators; and to describe the expectations of the programme managers with regard to standardization of information systems for leprosy control at an international level.

\section{Methods}

The study base was made up of the managers of leprosy control programmes throughout the world. As there was no exhaustive list of these programmes, the study population could not be randomly sampled. We therefore included in the study the 202 leprosy control programmes or projects which were in contact with our team as a WHO collaborating centre for the epidemiology of leprosy within the last 10 years. Three ILEP member associations* provided us with 66 additional addresses of correspondents who were not previously in contact with us.

In the first round, we sent a questionnaire to these 268 programme managers. It concentrated on information about the main characteristics of their programmes, the information systems in operation and the data regarded as indispensable or useful for programme monitoring. In the second round, another questionnaire collected information on additional project characteristics, the number of patients under MDT, the estimate of the real number of leprosy patients in the target population, the existence of any external supervision, and the need that was felt for a standardization of information systems at an international level. Nonetheless, the main part of the second questionnaire was aimed at reaching a consensus on the definition and the importance of the 12 indicators most frequently mentioned by the respondents to the first questionnaire. These 12 indicators were thus presented to programme managers with a strict definition,

* ILEP projects accounted for $27 \%$ of world figures of registered patients in 1993. All ILEP member associations $(n=20)$ were requested to provide the list of their projects or programmes, but only the American Leprosy Mission, the Leprosy Mission International (Divisions for Africa and Southern India) and the Nederlandse Stichting voor Leprabestrijding complied with our request. 
Table 1. Baseline characteristics of the respondents

\begin{tabular}{|c|c|c|c|}
\hline Characteristics & & $\begin{array}{l}\text { Respondents to the } \\
\text { 1st questionnaire } \\
n=64(\%)\end{array}$ & $\begin{array}{l}\text { Respondents to both } \\
\text { questionnaires } \\
n=37(\%)\end{array}$ \\
\hline Type of programme & $\begin{array}{l}\text { public } \\
\text { private } \\
\text { mixed }\end{array}$ & $\begin{array}{l}22(34) \\
24(38) \\
18(28)\end{array}$ & $\begin{array}{l}11(30) \\
15(41) \\
11(30)\end{array}$ \\
\hline $\begin{array}{l}\text { International assistance } \\
\quad \text { (multiple answers allowed) }\end{array}$ & $\begin{array}{l}\text { financing } \\
\text { personnel } \\
\text { drugs, materials } \\
\text { supervision }\end{array}$ & $\begin{array}{l}55(86) \\
23(36) \\
46(72) \\
26(41)\end{array}$ & $\begin{array}{l}33(89) \\
15(41) \\
27(73) \\
13(35)\end{array}$ \\
\hline Use of a computer & $\begin{array}{l}\text { yes } \\
\text { no }\end{array}$ & $\begin{array}{l}28(44) \\
36(66)\end{array}$ & $\begin{array}{l}15(40) \\
22(60)\end{array}$ \\
\hline Scope of the programme & $\begin{array}{l}\text { national } \\
\text { regional or local }\end{array}$ & $\begin{array}{l}\text { NA* }^{*} \\
\text { NA }\end{array}$ & $\begin{array}{l}10(27) \\
27(73)\end{array}$ \\
\hline $\begin{array}{l}\text { Type of external supervision } \\
\text { (multiple answers allowed) }\end{array}$ & $\begin{array}{l}\text { local health authorities } \\
\text { OMS/PAHO } \\
\text { ILEP member associations } \\
\text { other organizations } \\
\text { not identified }\end{array}$ & $\begin{array}{l}\text { NA } \\
\text { NA } \\
\text { NA } \\
\text { NA } \\
\text { NA }\end{array}$ & $\begin{aligned} & 18(49) \\
& 4(11) \\
& 12(32) \\
& 7(19) \\
& 7(19)\end{aligned}$ \\
\hline Regular use of ILEP B form & $\begin{array}{l}\text { yes } \\
\text { no }\end{array}$ & $\begin{array}{l}\text { NA } \\
\text { NA }\end{array}$ & $\begin{array}{r}33(89) \\
4(11)\end{array}$ \\
\hline Use of ILEP B form indicators & $\begin{array}{l}\text { yes } \\
\text { no }\end{array}$ & $\begin{array}{l}\text { NA } \\
\text { NA }\end{array}$ & $\begin{array}{r}33(89) \\
4(11)\end{array}$ \\
\hline Reported MDT coverage & $\begin{array}{l}\text { from } 50 \text { to } 100 \% \\
\text { below } 50 \%\end{array}$ & $\begin{array}{l}\text { NA } \\
\text { NA }\end{array}$ & $\begin{array}{r}33(89) \\
4(11)\end{array}$ \\
\hline
\end{tabular}

*NA, question not asked

given by us but still open to criticism. Our correspondents were requested to inform us whether they considered each of the 12 indicators as indispensable, useful or pointless for leprosy control. If they disagreed with the definition, they were invited to propose another one.

The study began in 1993. Replies sent back after 30 September, 1994 were not taken into account in the final analysis.

\section{Results}

Out of the 268 programme managers recruited for the study, $64(24 \%)$ and $37(15 \%)$ gave answers to the first and the second questionnaires, respectively. Replies to these two questionnaires came from 56 and 23 countries, respectively (Appendix 1). The 37 respondents to both questionnaires corresponded to a covered population of 346666387 people including 52949 registered leprosy patients. Out of these 37 respondents, 10 were the managers of national programmes (Benin, Congo, French Guyana, Malawii, Morocco, Mexico, Pakistan, French Polynesia, Sierra Leone, and Trinidad and Tobago) adding up to a total of 248139290 inhabitants. 
Baseline characteristics of our correspondents are shown in Table 1. There was a very slight predominance of private projects. A large majority of respondents were beneficiaries of international assistance from 16 out of the 20 ILEP member associations. Direct supervision by international agencies, most of them being ILEP member associations, was frequently mentioned. An important minority of the respondents had introduced computerized management of their programmes.

In the first round, more than 200 indicators of programme monitoring were proposed by the respondents. The definitions of these indicators were extraordinarily numerous and disparate. Even after grouping the indicators that showed similarities or concerned the same items (taking into account the most obvious synonyms and being very aware of the different wordings used by the respondents) we found 20 different terms for prevalence and 24 different terms for incidence (Appendix 2), 13 different terms for the proportion of children among leprosy patients, 14 different terms for the degree of disability, 10 different terms for MDT coverage, and 15 different terms for regularity or completion of treatment.

Among the indicators that the respondents to the first questionnaire spontaneously considered as indispensable, only the detection rate was mentioned by a majority of 39 respondents out of $64(61 \%)$. None of the other indicators were mentioned by such a high proportion of respondents. The indicators mentioned by at least $20 \%$ of them are the 'prevalence' (in fact the absolute or relative number of cases recorded) (26/64), the proportion of disabled people among the new cases $(25 / 64)$, the proportion of patients under MDT at the end of the year (19/64), the proportion of $0-14$ year-old children among the new cases (18/64), the proportion of cases recorded (or new cases) per form of leprosy (18/64), and the global proportion of disabled patients among newly-detected cases (13/64). As to the last indicator, the criteria 'WHO grade 2 disability' was explicitly mentioned by only 4 respondents. The cure rate was rarely mentioned (6/64). Other minority proposals highlighted the need for indicators of regularity of treatment or treatment completion.

As to the indicators considered usef ul, the respondents highlighted the importance of the proportion of children or disabled people among new cases (when these criteria had not been regarded as indispensable), the regularity of treatment, the frequency of relapse, the frequency of lepra reactions, and the incidence of other diseases during treatment.

Another list of 64 indispensable or useful indicators, different from those recommended by WHO or ILEP, has also been proposed. Most of these were not epidemiological or operational indicators suited to programme evaluation, but addressed problems such as case-holding (names, addresses, etc.), clinical assessment (number of skin lesions, state of nerves, etc.), programme setting (population, etc.), daily management (appointment timetable, etc.), or others ('spiritual data', etc.).

The following criteria did not make any difference between the respondents about the indicators regarded as indispensable or useful: using OMSLEP as an information system; benefitting from international assistance, or being a public, private or mixed leprosy control programme.

The extent of agreement of the 64 respondents to the first questionnaire and the 37 respondents to the second with the recommendations of international agencies such as WHO or ILEP is shown in Table 2. It is worth noting a progression towards a consensus on the main indicators after the second round. Only 4 out of 64 respondents $(6 \%)$ 
Table 2. Opinions of the respondents to the first and second questionnaires on the pertinence of the main indicators

\begin{tabular}{|c|c|c|c|c|c|c|}
\hline \multirow[b]{2}{*}{ Indicator } & \multirow[b]{2}{*}{ Recommendation } & \multirow{2}{*}{$\begin{array}{c}\begin{array}{c}\text { First round } \\
n=64\end{array} \\
\begin{array}{c}\text { Regarded as } \\
\text { indispensable }\end{array}\end{array}$} & \multicolumn{4}{|c|}{$\begin{array}{l}\text { Second round } \\
\quad n=37\end{array}$} \\
\hline & & & $\begin{array}{l}\text { Regarded as } \\
\text { indispensable }\end{array}$ & $\begin{array}{l}\text { Regarded as } \\
\text { usef ul }\end{array}$ & $\begin{array}{l}\text { Regarded as } \\
\text { pointless }\end{array}$ & No answer \\
\hline Prevalence & WHO/ILEP/Q1 & $26(41 \%)$ & $27(73 \%)$ & 9 & 1 & \\
\hline Detection & WHO/ILEP/Q1 & $39(61 \%)$ & $31(84 \%)$ & 4 & 1 & 1 \\
\hline \multicolumn{7}{|l|}{ Proportion of patients with grade 2} \\
\hline disabilities among new cases & WHO/ILEP/Q1 & $25(39 \%)$ & $21(57 \%)$ & 13 & 1 & 2 \\
\hline MDT coverage & WHO/ILEP/Q1 & $22(34 \%)$ & $18(49 \%)$ & 18 & & 1 \\
\hline \multicolumn{7}{|l|}{ Cure rate; Regularity MDT among PB } \\
\hline and/or MB patients; or MDT completion & WHO/ILEP/Q1 & $19(30 \%)$ & $20(54 \%)$ & 14 & 2 & 1 \\
\hline Relapse rate & WHO/ILEP/Q1 & $10(16 \%)$ & $13(35 \%)$ & 22 & 2 & \\
\hline \multicolumn{7}{|l|}{ Proportion of new MB leprosy cases } \\
\hline among new cases & ILEP/Q1 & $6(9 \%)$ & $12(32 \%)$ & 21 & 4 & \\
\hline \multicolumn{7}{|l|}{ Proportion of children $(0-14)$ among } \\
\hline Surveillance af ter treatment & Q1 & $4(6 \%)$ & $8(22 \%)$ & 16 & 13 & \\
\hline Care after treatment & Q1 & $2(3 \%)$ & $8(22 \%)$ & 24 & 4 & 1 \\
\hline Frequency of leprous reactions & Q1 & $2(3 \%)$ & $6(16 \%)$ & 27 & 4 & \\
\hline
\end{tabular}

WHO, indicators recommended by WHO Global Elimination Strategy; ILEP, indicators requested by ILEP B form; Q1, indicators most frequently mentioned in the first questionnaire (for the sake of simplification, we grouped together 'regularity MDT among PB patients' and 'regularity MDT among MB patients', regarded as two separate indicators by our respondents, and 'cure rate'). 
regarded the set of the 6 indicators considered by OMSLEP to be 'within the capabilities of most health services' as indispensable: prevalence rate, incidence or detection rate, proportion of multibacillary forms among newly-detected cases, proportion of children 0-14 years among newly-detected cases, proportion of disabled patients among newlydetected cases and one of the indicators proposed for monitoring multidrug therapy or relapse rate. ${ }^{2,11}$ Many criticisms, comments or alternative proposals about the 12 indicators presented and defined in the second questionnaire were put forward by almost all the respondents. Only a minority of these reflections were really relevant. The vast majority of them expressed some lack of understanding of what operational or epidemiological indicators are, and a tendency to increase the number of indicators or to unnecessarily make them more sophisticated.

Twenty-nine out of the 37 respondents to the second questionnaire $(78 \%)$ thought that leprosy control programmes should be free to devise the indicators considered appropriate to their activities, but they also agreed on providing the international organizations with a minimum set of identical basic indicators in order to allow international comparisons. In reply to the question of whether the international organizations (WHO, ILEP, etc.) should propose and recommend a standardized computerized information system, encompassing software and data base, 25 out of the 37 respondents $(68 \%)$ agreed with this proposal. Only 3 respondents $(8 \%)$ thought that leprosy control programmes should remain free to computerize their management tools according to their own preferences. Another 5 respondents (15\%) agreed with both proposals.

The second questionnaire also tried to explore programme managers' opinions about a controversial matter not directly related to the main topic of the study: the 'real' number of leprosy patients. The estimated number of hidden leprosy patients, expressed as a percentage of registered patients, varied greatly according to the programme. Nine out of the 37 respondents to the second questionnaire did not answer the question, and 6 claimed there were no unknown leprosy patient in their zones (those respondents were responsible for programmes practising mass surveys). As to the 22 respondents proposing an estimate, the proportion of unknown patients ranged from $9 \%$ to $143 \%$ (Sierra Leone), 246\% (Zaire, Kapolowe), 256\% (Barabanki District, Uttar Pradesh), 338\% (Nigeria, Kogi State), 500\% (Kwara State, Nigeria) and even $881 \%$ (Bangladesh). Seventeen of those 22 respondents gave some explanation about the calculations underlying their estimates. These explanations were very diverse, subjective, and lacking in any sound epidemiological basis.

\section{Discussion}

METHODOLOGICAL ISSUES OF THE STUDY

In designing and carrying out the study we were faced with three important concerns.

First, despite extensive mailing we failed to achieve a satisfying collaboration of programme managers contacted. Searching support from WHO, ILEP or other agencies would probably have improved the response rate. Nevertheless, such a low completion rate deserves serious attention because it could reflect some programme managers' lack of interest in, or understanding of interventions aimed at improving the quality of care.

Second, as we were unable to propose any convenient random sampling frame our results were likely to be distorted by subject selection. While the information necessary 
to assess or correct this source of bias is unavailable, it is worth noting that our study population encompasses at least one leprosy control programme in 20 out of the top 25 endemic countries' - as classified by WHO in $1993^{13}$ - in the first round. Moreover, the 12 respondents to the second questionnaire who were from these 'top endemic countries' were in charge of $2.2 \%$ of the total number of registered leprosy patients in these countries (Appendix 3). Accordingly, we think our results merit attention, whatever the potential for selection bias.

Third, because of the relatively low proportion of response achieved in the first round and the high occurrence of drop-outs registered in the meantime, we decided to stop the study after the second round. Such a shortcoming could well be explained by the apparent complexity of the qualitative method we tried to use for reaching a consensus among respondents. For instance, a response to the second questionnaire implied an indepth understanding of the contents of an interim report based on the replies to the first questionnaire. Although we cannot rule out a self-selection of the respondents, an assessment of the direction of this bias is feasible. As the second questionnaire required that $\mathrm{PB}$ and $\mathrm{MB}$ be distinguished and that MDT coverage be assessed, it appears to have selected the respondents who were most advanced in MDT, most of ten linked up with ILEP and receiving external supervision. However, it did not select the 'best students', i.e. those respondents to the first questionnaire who mentioned the basic WHO or ILEP indicators as indispensable, and rigorously defined them.

\section{PROGRAMME MANAGERS' OPINIONS AND INTERNATIONAL RECOMMENDATIONS}

The main finding of the study is the great diversity of answers to the question: what information is, in your view, indispensable for controlling leprosy and monitoring your programme? As some of the numerous definitions of, say, prevalence given in Appendix 1, might overlap, it could be argued that we are exaggerating the real discrepancies between the respondents. But even so, there is still a confusion between the absolute number of cases, point prevalence, period prevalence on the one hand, and registered cases, treated cases and cases needing care on the other hand. Let alone all the definitions which are definitely unorthodox.

The indicators requested by the well-known ILEP B form, which is mandatory to be completed by projects or programmes in order to keep on getting funds from ILEP member associations, did not spontaneously arouse a great interest from the respondents to the first questionnaire. The WHO latest recommendations were not available at the time of this study ${ }^{14}$ but most of them had been internationally recommended for a long time, and used by OMSLEP. With the exception of detection rate, none of the WHO/ILEP indicators were mentioned as indispensable by a majority of the respondents. Moreover, while some have recently proposed to restrict the basic information for leprosy control to only two indicators, i.e. the rate of newly-detected cases and the proportion of patients cured, ${ }^{10}$ only $61 \%$ of the respondents to this study would have agreed with the first indicator and less than $20 \%$ with the second one.

Though proposed in the second round of the study, none of the indicators most often regarded as indispensable by the respondents to the first questionnaire succeeded in achieving a complete consensus, even detection rate or prevalence rate. MDT coverage, MDT being the core of the current strategy against leprosy, is accepted as an indispensable indicator by only half of the second round of respondents. 
How can these results be explained? We think it is not merely a problem of inadequate wording. It can be feared that, behind the wide disparities in the responses and the lack of precision of most proposals, different understandings of the phenomena to be measured are at play. One must wonder whether the real meaning of programme monitoring is in any case rightly understood. First, in spite (or because ?) of numerous international meetings and WHO expert committee recommendations, there is still no general agreement on the set of indicators to be systematically collected in leprosy control programmes. Recommendations from ILEP are not exactly the same as those from OMSLEP, they differ still from the many and sometimes changing recommendations from WHO successive technical reports on leprosy. If experts' opinions do not converge, we cannot expect programme managers in the field to comply with contradictory or overlapping requirements. Second, there is a problem of education and training. Even when they have to use a clearly defined set of indicators, such as in ILEP B form, not all programme managers seem to understand correctly the fundamental requirements of data collection. They still keep on proposing numerous, inadequate indicators and definitions, and they do not reach full consensus on essential indicators in the second phase of the study. Third, there is a tendency for the central levels of leprosy control administration or donor agencies to request far too many data and calculations from field managers. Most of these indicators are just useless in decision making, as pointed out by Feenstra, ${ }^{7}$ but keep on clouding the issues in leprosy control management.

An additional concern is with the number of hidden cases of leprosy. The figures reported are only minimally informative and most of the explanations underlying the calculation of the real number of leprosy patients are not sound. It is likely that many programme managers are not sufficiently familiar with the basic concepts and methods of descriptive epidemiology. When, in particular, the 6 respondents responsible for programmes practising intensive mass surveys declared that all leprosy patients are known to them, it led us to doubt whether these mass surveys are really capable of detecting all leprosy patients. We think that, if those surveys were to be carried out, which is questionable, they would create a false sense of security as to a complete coverage of the population.

\section{NEEDS OF PROGRAMME MANAGERS}

The surprising agreement of the respondents on the necessary degree of standardization of data collection and computerization offers an opportunity for WHO, ILEP and other international agencies to make new, limited, decision-making oriented and welldefined proposals about leprosy control indicators. An up-dating of OMSLEP system, or any other system like EPI-Info-based software, compatible with ILEP requirements and with future perspectives in integration of leprosy control into general health services, as well as openness to a synergy with tuberculosis control, could be a very interesting issue.

\section{Conclusion}

With this study we conclude that the accuracy and validity of the information collected from leprosy control programmes are not satisfactory. Yet this information is used to 
support the implementation of the elimination strategy, i.e. to determine priorities, follow-up progress, and make recommendations. These results underscore the need for putting some effort into the building of an agreement between WHO, international agencies and national leprosy control programmes on the indicators to be effectively and systematically used. Programme managers in the field are obviously open to greater intervention by international organizations to enhance the cohesion of data collection and to promote a minimal standardization in computerized programme management. International aid agencies in leprosy control should pay more attention to the need expressed by programme managers for support and training in dealing with health information systems. It also seems to be important that programme operators be given the material and operational possibilities to carry out surveys on prevalence based on sound methodology and to discourage the unscientific use of 'mass surveys' as a way of estimating prevalence.

In addition, we think that the conclusions of this study could equally apply to activities other than leprosy control programmes and prove relevant for any health information system in developing countries.

\section{Acknowledgments}

This work was supported in parts by grants from the following ILEP member associations: Association Française Raoul Follereau, Damien Foundation Belgium, and Secours aux Lépreux Canada.

We kindly acknowledge the advice of Professor Michel Lechat, former head of the Department of Epidemiology, Faculty of Medicine, Catholic University of Louvain, and the support received from all respondents who participated in the study.

We thank Catherine Gelin for her assistance with data collection and analysis.

\section{References}

1 44th World Health Assembly. Agenda Item 17.2 11 th Plenary Meeting. 13 May 1991. Ref.: A44/VR/11.

2 Noordeen SK. Elimination of leprosy as a public health problem. Editorial. Lepr Rev 1992; 63: 1-4.

${ }^{3}$ World Health Organization. A guide to Leprosy control. Geneva: WHO, 1988.

4 World Health Organization. Epidemiology of leprosy in relation to control. Technical Report Series 716. Geneva: WHO, 1985.

5 Martineau-Needham D, Lacey S. Leprosy control activities of the International Federation of Anti-leprosy Associations. Rapport trimestriel des statistiques sanitaires mondiales 1991; 44: 36-46.

6 World Health Organization. Report of consultation on monitoring and evaluation of leprosy control. Geneva: WHO; WHO/CTD/LEP/92.3: 10-11.

7 Feenstra P. Needs and prospects for epidemiological tools in leprosy control. Lepr Rev 1992;63 (supplement): $3-10$.

8 Jesudasan K. Estimation of the leprosy problem through health services data. Lepr Rev 1992; 63 (Supplement): 21-2.

9 Myo Thet Htoon. Indicators for use in leprosy control programmes. Lepr Rev 1992; 63 (Supplement): 73-76.

$1014 \mathrm{e}$ Congrès International de Léprologie. Comptes rendus des ateliers (2e partie). Directives pour les administrateurs de la lutte contre la lèpre. Acta Leprologica 1994; 9: 66-68.

11 Fine PEM. Reflections on the Elimination of Leprosy. Int J Lepr editorial. 1992; 60: 71-80.

12 Lechat MF, Misson CB, Sansarricq H, Declercq E, Vanderveken M. OMSLEP. Recording and reporting system for leprosy patients. Brussels: Catholic University of Louvain, 1981, 1983 and 1987.

13 World Health Organization. Weekly Epid Rep 1993; 25: 184.

14 World Health Organization. Global Strategy for Elimination of Leprosy as a Public Health problem. Geneva: WHO; WHO/CTD/LEP/94.2. 
Appendix 1-Geographic distribution of the respondents

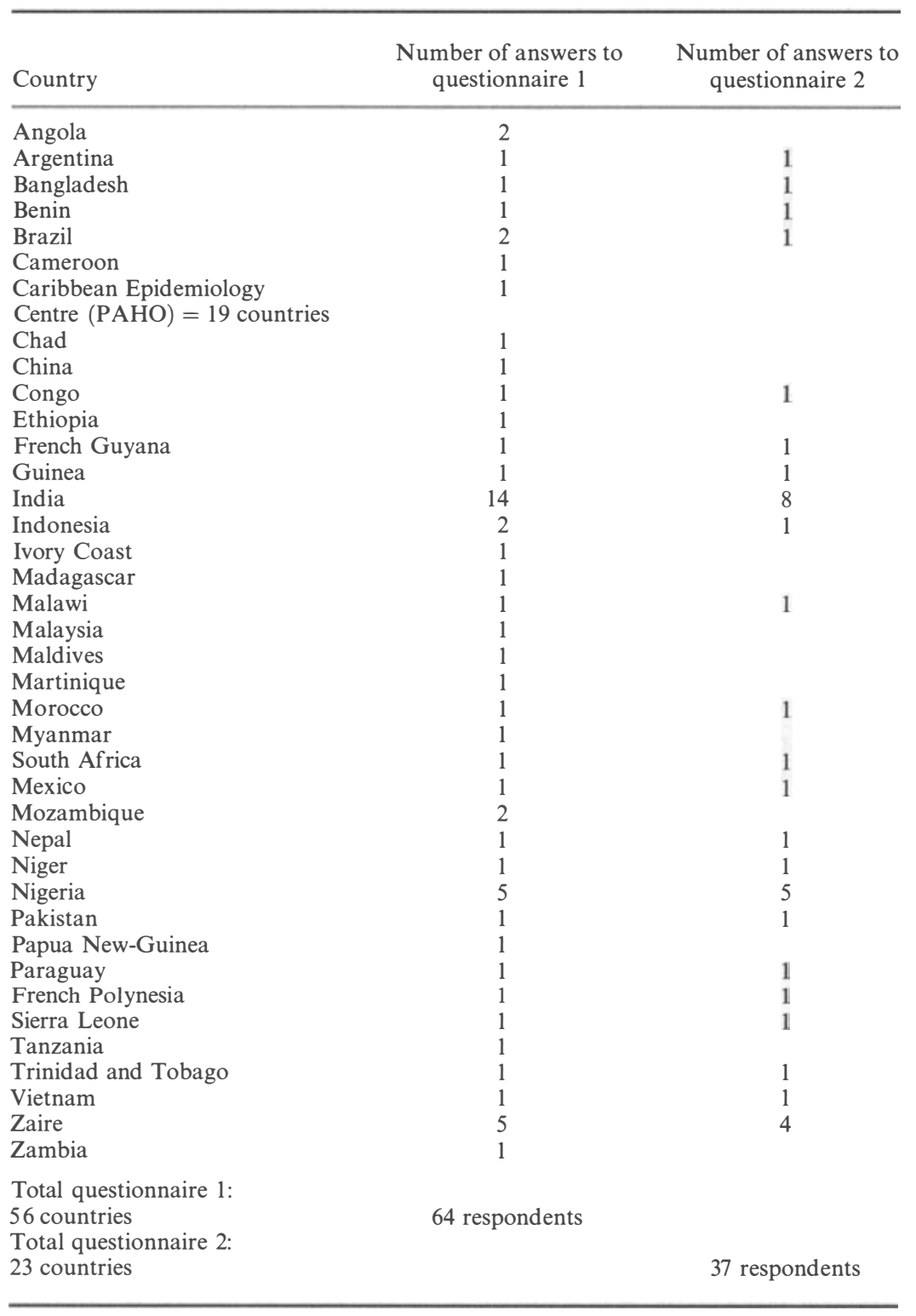


Appendix 2-List of 20 different groups of terms for prevalence and 24 groups of terms for incidence proposed by the 64 respondents to the first questionnaire

\section{Prevalence}

Global prevalence

Active prevalence

Prevalence rate

Prevalence rate per year

Prevalence rate of recorded cases

Prevalence rate of recorded cases at the end of the year

Number of cases recorded

Number of cases recorded at a certain date

Number of cases recorded during a particular period

Number of cases recorded during the year

Number of cases being treated

Number of cases being treated or that need treatment

Number of cases being treated at a certain date

Number of cases being treated during the year

Number of cases of leprosy patients recorded/population

Prevalence rate of cases needing chemotherapy at the end of the year par 10,000 inhabitants

Prevalence rate of cases registered for chemotherapy

Number of cases registered for chemotherapy every year

Requirement in terms of medicines (= cases needing chemotherapy?)
Incidence

Global incidence

Incidence of new cases

Incidence rate

Incidence rate per year

Detection

Detection rate

Detection per year/10,000 inhabitants

Detection rate of new cases

Number of patients never treated before

Number of new cases

Number of new cases discovered

Number of new cases recorded every year

Number of new cases reported annually

Number of new cases detected within a year

Number of new cases/year

Number of new cases detected/year/1,000 inhabitants

Number of new cases of leprosy discovered during the month, quarter, year $(\mathrm{PB}+\mathrm{MB})$

Number of new cases per quarter/1,000 inhabitants

Number of new cases/population

Number of new cases/type of leprosy

Coefficient of annual registration of new cases

Detection activities for all methods

Detection rate for all patients 
Appendix 3-Estimated number of leprosy patients in the top 25 endemic countries and participation of programmes from these countries in the study

\begin{tabular}{|c|c|c|c|c|c|c|c|c|}
\hline \multirow{2}{*}{$\begin{array}{l}\text { The top } 25 \text { endemic } \\
\text { countries } \\
\text { in } 1993 \text { (WHO) } \\
\text { (1) } \\
\text { India }\end{array}$} & \multicolumn{2}{|c|}{$\begin{array}{l}\text { Countries represented in } \\
\text { responses to } \\
\text { questionnaire } 1 \text { and } \\
\text { (number of responses) } \\
\text { (2) }\end{array}$} & \multicolumn{2}{|c|}{$\begin{array}{c}\text { Countries represented in } \\
\text { responses to } \\
\text { questionnaire } 2 \text { and } \\
\text { (number of responses) } \\
\text { (3) }\end{array}$} & \multirow{2}{*}{$\begin{array}{l}\text { Number of } \\
\text { estimated cases } \\
\text { in } 1993 \\
\text { (WHO) } \\
(4) \\
1,677,000\end{array}$} & \multirow{2}{*}{$\begin{array}{c}\text { Number of registered } \\
\text { cases (WHO) } \\
\text { (reference years: } \\
1989-92) \\
(5) \\
1,459,338\end{array}$} & \multirow{2}{*}{$\begin{array}{l}\text { Number of registered } \\
\text { cases as declared by } \\
\text { respondents to } \\
\text { questionnaire } 2 \\
(6) \\
5,457\end{array}$} & \multirow[t]{2}{*}{$\begin{array}{l}\text { Proportion } \\
(6 / 5) \%\end{array}$} \\
\hline & India & (14) & India & $(8)$ & & & & \\
\hline Brazil & Brazil & (2) & Brazil & (1) & 283,800 & 250,066 & 2,247 & \\
\hline Indonesia & Indonesia & (2) & Indonesia & (1) & 170,000 & 74,683 & 3,202 & \\
\hline Bangladesh & Bangladesh & (1) & Bangladesh & (1) & 136,000 & 19,932 & 836 & \\
\hline Myanmar & Myanmar & (1) & & & 120,000 & 57,389 & & \\
\hline Nigeria & Nigeria & (5) & Nigeria & (5) & 63,000 & 62,080 & 2,972 & \\
\hline Sudan & & & & & 32,000 & 31,028 & & \\
\hline Philippines & & & & & 30,000 & 14,925 & & \\
\hline Iran & & & & & 30,000 & 10,487 & & \\
\hline Vietnam & Vietnam & (1) & Vietnam & (1) & 30,000 & 18,342 & 3,762 & \\
\hline Madagascar & Madagascar & (1) & & & 30,000 & 5,290 & & \\
\hline Egypt & & & & & 30,000 & 8,696 & & \\
\hline Nepal & Nepal & (1) & Nepal & (1) & 29,000 & 22,812 & 4,651 & \\
\hline China & China & (1) & & & 25,000 & 20,003 & & \\
\hline Zaire & Zaire & (5) & Zaire & (4) & 25,000 & 7,736 & 7,053 & \\
\hline Mozambique & Mozambique & (2) & & & 25,000 & 19,216 & & \\
\hline Colombia & (PAHO) & (1) & & & 20,000 & 18,983 & & \\
\hline Mexico & Mexico & (1) & Mexico & (1) & 20,000 & 16,732 & 9,532 & \\
\hline Ethiopia & Ethiopia & (1) & & & 20,000 & 12,041 & & \\
\hline Guinea & Guinea & (1) & Guinea & (1) & 15,000 & 6,942 & 1,678 & \\
\hline Ivory Coast & Ivory Coast & (1) & & & 15,000 & 6,483 & & \\
\hline Mali & & & & & 15,000 & 12,710 & & \\
\hline Chad & Chad & (1) & & & 11,000 & 6,952 & & \\
\hline Niger & Niger & (1) & Niger & (1) & 10,000 & 6,468 & 305 & \\
\hline Pakistan & Pakistan & (1) & Pakistan & (1) & 10,000 & 9,611 & 5,708 & \\
\hline Total 25 & Total 20 & & Total 12 & & $2,871,800$ & $2,178,945$ & 47,403 & $2.2 \%$ \\
\hline
\end{tabular}

